\title{
Revista
}

\section{O JULGAMENTO DE SÓCRATES: SÓCRATES E O CONCEITO DE JUSTIÇA: A REPERCUSSATO DO JULGAMENTO ANTIGAMENTE E SUA INTERPRETAÇÃO ATUAL}

\author{
THE JUDGMENT OF SOCRATES: \\ SOCRATES AND THE CONCEPT OF JUSTICE: THE \\ REPERCUSSION OF THE JUDGMENT ANCIENTLY AND ITS \\ CURRENT INTERPRETATION \\ Ricardo Santos David ${ }^{1}$
}

\begin{abstract}
Recebido em: 09/04/2017 Aceito em: 14/10/2017 ricardosdavid@hotmail.com

Resumo O presente artigo tem por intuito analisar o Julgamento de Sócrates e a sua interpretação na atualidade. Discorre-se inicialmente acerca do conceito de justiça para o filósofo Sócrates. Em seguida, analisa-se o julgamento deste, comentando os principais pontos. Por fim, faz-se uma comparação entre a repercussão que o julgamento teve antigamente, com a que ele tem na atualidade, procurando demonstrar tal evolução.
\end{abstract}

Palavras-chave: Julgamento. Justiça. Atualidade. Sócrates. Evolução.

Abstract: The purpose of this article is to analyze the Socrates Judgment and its interpretation today. We first discuss the concept of justice for the philosopher Socrates. Next, it analyzes the judgment of this, commenting the main points. Finally, a comparison is made between the repercussions that the judgment had in the past, with which it has at the present time, trying to demonstrate such evolution.

Keywords: Judgment. Justice. Actuality. Socrates. Evolution.

\section{INTRODUÇÃO}

Breve histórico O filósofo grego Sócrates, encontra-se ínsito na história da humanidade como sendo um divisor de águas. Da mesma forma que a história, posteriormente, veio a dividir os acontecimentos terrestres nos tempos antes e depois de Jesus Cristo, dizemos de pré e pós Sócrates. Sócrates nasceu por volta de 470 e morreu em 399 a.C., deixando mulher e três filhos. Quando jovem, estudou as filosofias de então em voga, dos que hoje chamamos de "filósofos présocráticos". O contexto sócio-político em que situa a figura de Sócrates começa no assim chamado século de Péricles, esse distante século $V$ a.C., em que Atenas atinge o seu apogeu. Previamente tinham deixado a sua pegada Tales, Anaximandro, Anaxímenes, Heráclito, etc., todos a receberem, posteriormente o rótulo de pré-socráticos. Chega-se a esse século maravilhoso dominado no ambiente cultural por Anaxágoras, que seria um dos preceptores de Péricles. E em vinte anos de governo de Péricles, ver-se-ia subir o que até hoje nos alimenta, ou seja, a cidade de Atenas. Nada foi tão profundo, tão potente, que iluminou o essencial da forma de viver da civilização ocidental. Em Atenas se produz um desses momentos de ouro que ciclicamente aparecem em diferentes pontos da Terra.

\footnotetext{
${ }^{1}$ Florida Christian University - FCU - Orlando - Flórida - Estados Unidos
} 
Personagem estanho, Sócrates resistia como ninguém ao sono, ao cansaço, ao frio, não precisava de nenhum luxo e quando o convidavam a algum banquete tomava uma taça de vinho após outra, mantendo-se sempre sereno, nunca tendo sido visto em estado de embriaguez. Por volta dos 50 anos, seu amigo Querefonte fez uma consulta muito curiosa ao oráculo de Delfos. Ele perguntou ao Deus Apolo se havia um homem mais sábio do que Sócrates. O oráculo respondeu que não. Não havia ninguém mais sábio do que ele. Quando Querefonte chegou a Atenas foi correndo the dizer o que a pítia havia the respondido; Sócrates the diz que o deus estava brincando, pois isso era impossível "Como serei eu o homem mais sábio de toda a Grécia?". E foi. Sócrates foi beneficiado por ter vivido numa época áurea para a Grécia, na qual grandes artistas embelezavam Atenas, os pensadores propagavam suas ideias em outras regiões da Grécia e as grandes tragédias eram encenadas. Neste rico cenário, Sócrates, que nunca escreveu nada e cuja passagem pela Terra nos é dada através de fragmentos de escritos de seus discípulos, tendo na obra de Platão, o seu mais renomado discípulo, o grande legado que foi deixado para que pudesse ser admirado como é, após mais de dois mil e quinhentos anos. As palavras do oráculo, anteriormente descritas, soaram para o filósofo como a enunciação de uma missão. Esta era ir em busca dos que se julgavam sábios e mostrar-Ihes a sua ignorância. Na praça publica de Atenas - chamada pelos gregos de ágora Sócrates questionava os seus conhecimentos até provar à própria pessoa - e a quem o assistia que a sua sabedoria era ilusória. Segundo Sócrates, as crenças humanas podem esconder desejos secretos, que usam o pensamento para geração de ideias pretensamente lógicas. Parta evitar esse engodo, Sócrates dizia que não poderia haver filosofia sem autoconhecimento. E aí surge outra frase famosa do filósofo: "Conhece-te a si mesmo".

Sócrates dedicava-se muito mais a perguntar do que a responder, deslocando a reflexão filosófica da natureza - priorizada pelos pré-socráticos - para o homem, alegando que as questões relativas ao ser humano são as que merecem mais reflexão. Ele não estava mais preocupado com a origem do cosmos (como as pessoas no tempo da mitologia) tampouco com o elemento que seria a essência de tudo. Para ele, o fundamental era a reflexão sobre a vida da polis (cidade), os costumes e comportamentos. Os sofistas Os gregos acreditavam que seus valores eram superiores aos dos demais povos. As colônias, o comércio, as guerras e as viagens fizeram com que esse povo passasse a ter contato com outras culturas. Mas a derrota ateniense na guerra do Peloponeso (404 a.C.) mudou muita coisa na vida dessa gente. Dois conceitos que anteriormente pareciam ligados, separam-se. Tratam-se dos conceitos de phýsis (natureza) e nómos (lei). Acreditava-se previamente que a lei, as instituições de um Estado baseavam-se na natureza, e que por assim estarem, seriam corretas, sendo incorretas àquelas que dela se afastassem. Nesse contexto surgem os sofistas, educadores de jovens que faziam exibições públicas de eloquência, visitando cidade por cidade. Alguns alunos de Sócrates pretenderam entrar para a política e alguns pretenderam tornarem-se sofistas. Os chamados sofistas pretendiam ensinar gramática, religião, interpretação dos poetas, porém, principalmente, a virtude política. Eles cobravam por seu trabalho, o que os diferenciava da 
O julgamento de Sócrates: Sócrates e o conceito de justiça: a repercussão do julgamento antigamente e sua interpretação atual

lavra socrática. Eram céticos quanto à religião e quanto à fundamentação das instituições humanas. Fundamentalmente, os sofistas tinham no ensinamento de como ganhar nos tribunais e como agir para fazer carreira política, na arte da retórica, o sumo da sua cátedra. Esse modelo de ensinamento fez sucesso, sobretudo na democracia ateniense.

Foram expoentes dos sofistas nomes como Protágoras, Górgias, Pródico, Hípias, dentre outros. O interrogador magistral Muitos rotularam Sócrates como sendo um sofista, pois Ele assim poderia aparentar ser, ao ensinar aos jovens na praça; porém algumas diferenças são marcantes e que o distancia da concepção sofista. Sócrates não pretendia ensinar nenhum saber positivo aos jovens, mas antes tentar livrá-los dos pretensos conhecimentos que esses jovens criam possuir e que, na verdade, eram apenas conhecimentos ilusórios. O Filósofo grego desenvolveu - (desenvolver significa tirar a casca de algo, num sentido primeiro desta palavra) - uma investigação compulsiva pela significação das palavras. Seu objetivo, porém, não era chegar a definições e conceitos finais. O que the interessava era apenas a troca de ideias, a conversa. A meta da discussão não era o assunto em si, mas o interlocutor. Era um método complexo (que significa o que é tecido junto) e Sócrates assim o desenvolveu. Se conseguisse mostrar ao seu interlocutor que ele era detentor de falsas verdades, que o seu conhecimento era limitado e que seus conceitos eram obscuros, Sócrates davase por satisfeito. Pois, para Ele, o reencontro consigo mesmo só se daria a partir da consciência da própria ignorância ("Só sei que nada sei"). Por essa razão seu método começa pela fase considerada "destrutiva", a ironia, termo que em grego significa "perguntar". Ao colocar uma questão sobre uma determinada virtude, e progressivamente, com hábeis perguntas, ocorre-se o desmonte das certezas até o outro reconhecer a própria ignorância. No final, nenhuma definição ficará de pé. Mas o interlocutor de Sócrates passa por uma terapia e se dá conta de que ele, na verdade, não sabe o que pensava saber. Sócrates, por afirmar nada saber, não ensina nada de positivo ao interlocutor, mas o livra da ilusão de ter o conhecimento que, de fato, não tem.

O que é justiça? Vale a apena ser justo? O justo pertence ao bem? O que mais vale: a corrupção ou a justiça? A idéia de justiça de Sócrates advém da Grécia Antiga. Na obra "A República" do socrático Platão, o ideal de justiça é o tema em questão, sendo Sócrates o personagem principal. O julgamento de Sócrates é um dos pontos marcantes deste trabalho, pois a partir de suas ideias, ideologias, pensamentos e ensinamentos, ele foi condenado à pena de morte. Sócrates é de fundamental importância para o desenvolvimento da ideia de justiça. Baseado em estudos e em análise das cidades e dos homens, ele dá inicio a uma série de pesquisas que auxiliaram no desenvolvimento de uma ciência estruturada e baseada no estudo da justiça. No contexto geral da filosofia, o julgamento deste filósofo é um dos temas de maior importância na difusão e estruturação dessa ciência. Sabendo que a ideia de justiça propagada pela Filosofia, tem espaço no dinamismo jurídico enfrentado por nós atualmente, através dos pensamentos de Sócrates entenderemos de que forma, essa filosofia será encaixada na cultura moderna. Sócrates foi condenado à morte por acusações que consistiam em ocupar seu tempo com fenômenos celestes, investigar o que se passava debaixo da terra, sua capacidade de fazer prevalecer sobre as boas coisas, as coisas más; ensinar essa doutrina aos outros e de instruir as pessoas a troco de dinheiro. No entanto, o mesmo se auto defendeu e colocou essas acusações abaixo com seus argumentos de total fundamentação.

Revista do Direito [ISSN 1982-9957]. Santa Cruz do Sul, v. 2, n. 52, p. 60-70, maio/set. 2017. https://online.unisc.br/seer/index.php/direito/index 
Porém esse caso não aconteceu só com Sócrates, é uma coisa corriqueira hoje em dia onde pessoas usam diversos argumentos infundáveis para conseguir uma condenação de um indivíduo mesmo de forma suspeita. Abordar-se-á também a questão da corrupção levando para o lado da justiça, já que o juiz que acabou condenando Sócrates the propôs que parasse de expor sua sabedoria - motivo principal que o levou a condenação. Para fechar nosso trabalho analisaremos a correlação desse julgamento nos dias atuais, se isso ainda ocorre mesmo com todo avanço que obtivemos durante esses milênios e colocaremos em xeque muitos juízes que usam do seu "poder" - status, para sentenciar pessoas à condenação, devido a interesses sobrepostos.

\section{O CONCEITO DE JUSTIÇA PARA SÓCRATES}

Para trazer à tona a "verdade" do sujeito, o que the vai à alma, Sócrates cria um método específico, a partir da sua inteligência e perspicácia apuradas. Esse método ficou conhecido por maiêutica (em grego "parto"), que significa parto de ideias, em homenagem à sua mãe, que era parteira; segundo Sócrates, se ela fazia parto de corpos, ele "dava à luz" ideias novas. O diálogo socrático tem como objeto purificar o discurso, livrá-lo das suas contradições, partindo do confronto de exemplos e opiniões até chegar a definições universais, a serem aplicadas a todos os seres humanos. Sócrates compreendeu que as condições de uma ciência moral residiam na constituição, por via indutiva, dos conceitos universais, como a coragem, a justiça, etc. $\mathrm{O}$ indivíduo libertado assim da particularidade da sua opinião pode viver de acordo com a razão, sabendo o que pode e o que deve fazer sem se contradizer. Essa tarefa que consiste na construção de uma ciência moral é fundamental para o filósofo grego, que possui a convicção profunda de que a virtude ensina que ninguém é mau voluntariamente e de que o mal reside exclusivamente na ignorância de si, quando o mesmo ser arvora num pretenso saber, que, efetivamente, não detém. A justiça socrática Por seu caráter desafiador e questionador, Sócrates foi considerado um elemento corruptor da juventude, desafiando preconceitos sociais da época. No ano de 399 a.C., um tribunal formado por cidadãos provenientes de dez tribos que compunham a população de Atenas, reuniu-se para julgar Sócrates. Ele fora acusado por três elementos da sociedade ateniense - Meleto, Ânito e Lícon - de não reconhecer os deuses do Estado, de introduzir novas divindades e de corromper a juventude. Fez a própria defesa, mas foi condenado à morte. Teve a oportunidade de comutar sua pena, de fugir, mas não fez nada disso, enfrentando a sua sentença, preferindo morrer a admitir a culpa de algo que não tinha feito.

Indubitavelmente, frente ao clima de liberdade imperante na vida pública grega, a filosofia na Grécia possuía riqueza imensurável, advindo, portanto, as ideias de Justiça. O permanente anseio de justiça justifica as teorias escritas por Platão. O pensamento de Sócrates, neste contexto, que nada deixou escrito, se extrai dos diálogos de Platão, principalmente na obra A República. O que é justo e o que é injusto? Para Sócrates, a ideia de justiça é bem simples, mas advém de vários fatores. A justiça é, segundo ele, a base para todas as virtudes a que o homem quer ter. A justiça deveria estar contida nas virtudes (temperança[3], valor - o amor das - e sabedoria - gosto pelo saber) e na alma

Revista do Direito [ISSN 1982-9957]. Santa Cruz do Sul, v. 2, n. 52, p. 60-70, maio/set. 2017. https://online.unisc.br/seer/index.php/direito/index 
(dividida em desejo, coragem e razão) do homem, sendo que a virtude que deveria prevalecer seria a justiça [4]. O que seria justiça? O justo se dá a partir de uma análise do homem na sociedade, é baseado em um conceito antropológico, não se remetendo a conceitos fechados e absolutos. A cidade, por ser reflexo do homem, é justa se estiverem homens justos vivendo nela. Pergunta-se: o justo é mais feliz e vive melhor do que o injusto?

Cada coisa possui uma função que the é própria e nenhuma outra pode desempenhar aquela função melhor do que ela. [...] a função de cada coisa é também sua virtude [...] a alma tem também funções específicas como guiar, comandar, tomar decisões, que só podem ser desempenhadas por ela. [...] a função mais elevada da alma é manter a vida, de modo que, se nada pode exercer a função melhor do que ela, então aquela função deve ser considerada a sua virtude. [5] Segundo Sócrates, a premissa básica para que se tenha uma sociedade justa, vem da ideia de uma República bem organizada, na qual a atitude do justo é atar dentro de suas aptidões, mas agindo pensando no 'bem comum' (“um por todos e todos por um”). [...] É, portanto, evidente que é sábia, corajosa, sensata e justa. Mas escuta, e diz se eu digo bem. O princípio que de entrada estabelecemos que devia observar-se em todas as circunstâncias, quando fundamos a cidade, esse princípio é, segundo me parece, ou ele ou uma das suas formas, a justiça. Ora nós estabelecemos, segundo suponho, e repetimo-lo muitas vezes, se bem te lembras que cada um deve ocupar-se de uma função na cidade, aquela para a qual a sua natureza é mais adequada. [...] Além disso, que executar a tarefa própria, e não se meter nas dos outros, era justiça. Essa afirmação escutamo-la a muitas outras pessoas, e fizemo-la nós mesmos muitas vezes. [...] Logo, esse princípio pode muito bem ser, de certo modo, a justiça: o desempenhar cada um a sua tarefa. [6] O maior dos danos que poderia ser acometido a cidade seria a injustiça. Teria cometido injustiça, aquele que não cumprisse a sua função natural na cidade, causando confusão entre as três classes de virtudes (naturezas da cidade), o que geraria danos terríveis.

A cidade se tornaria justa se cada um cumprisse a sua tarefa, fazendo aquilo que the foi incumbido de acordo com a sua natureza, pois estaria imposta a noção de justiça. [7] — Não o afirmemos com toda a segurança, mas, se reconhecermos que esta concepção, passando a cada indivíduo em particular, também aí será justiça, já concordaremos - pois por que não o diremos? Caso contrário, então examinaremos qualquer outra questão. Mas agora, levemos a cabo esta investigação, da qual pensávamos que, se tentássemos contemplar a justiça num dos seus maiores possuidores, antes de a vermos aí, se tornaria mais fácil vê-la num indivíduo. E pareceu-nos que tal possuidor era a cidade, e assim fundamos uma o melhor possível, perfeitamente cientes de que a justiça estaria nela, se fosse boa. Aquilo que aí se nos revelou, vamos transferi-lo para o indivíduo, e, se se acertar, bom será. Mas se a justiça se manifestar como algo de diferente no indivíduo, regressaremos novamente à cidade, para tirar a prova, e em breve, comparando-as friccionando-as uma contra a outra, como de uma pederneira, faremos saltar a faísca da justiça. $E$, depois de ela se ter tornado bem visível, fixá-la-emos em nós mesmos. [8] Dessa forma, o homem justo deverá assemelhar-se à cidade justa. A cidade é justa quando há, dentro dela, presentes as naturezas da 
temperança, da coragem e da sabedoria. O homem que tivesse na alma essas três virtudes seria considerado como justo. Agora resta saber se o homem possui em si essas três partes ou não. A cidade assim o é porque o homem habita nela. Logo, não há que se discutir se ao homem deve ser atribuída ou não essas características. No entanto, difícil seria determinar cada uma dessas no indivíduo. "Compreendemos, graças a um; irritamo-nos, por outro dos que temos em nós; desejamos, por um terceiro, o que toca aos prazeres da alimentação, da geração e quantos há semelhantes a estes; ou então praticamos cada uma destas ações com a alma inteira. Isto é que será difícil de determinar convenientemente".[9] A alma humana é composta por três elementos, quais sejam: a razão, o desejo e a coragem.[10] A razão e o desejo brigam entre si, não estando do mesmo lado, não se associam, ao contrário da coragem, que luta ao lado da razão. A coragem, o medo, a ira, apesar de por vezes caminharem com a razão, segundo Sócrates, não se confundem entre si, pois "tal como, na cidade, esta se compunha de três classes: a negociante, a auxiliar e a deliberativa; também na alma a terceira servia este elemento irascível, auxiliar do racional por natureza, quando não foi corrompido por uma má educação? [...] se ele se revelar diferente do racional, como já se mostrou distinto do concupiscível”. [11] [...] É, como dissemos, uma mistura de música e de ginástica que harmonizará essas partes, uma fortalecendo-a e alimentando-a com belos discursos e ciência, outra, abrandando-a com boas palavras, domesticando-a pela harmonia e pelo ritmo. [...] E estas duas partes, assim criadas, instruídas e educadas de verdade no que lhes respeita, dominarão o elemento concupiscível (que, em cada pessoa, constitui a maior parte da alma e é, por natureza, a mais insaciável de riquezas) e hão de vigia-lo, com receio que ele, enchendo-se dos chamados prazeres físicos, se torne grande e forte, e não execute a sua tarefa, mas tente escravizar e dominar uma parte que não compete à sua classe e subverta toda a vida do conjunto. [12] A justiça é essa força que produz tais homens e cidades.

A justiça de dá no interior do homem, aquilo que verdadeiramente lhe pertence, sem que ninguém interfira nas atividades dos outros, "mas depois de ter posto a sua casa em ordem no verdadeiro sentido, de ter autodomínio, de se organizar, de se tornar amigo de si mesmo, de ter reunido harmoniosamente três elementos diferentes, exatamente como se fossem três termos numa proporção musical, o mais baixo, o mais alto e o intermédio" e outros possíveis que possam existir para permear, e ligar aos outros, gerando-os, de muitos que eram uma perfeita "unidade, temperante e harmoniosa, só então se ocupe (se é que se ocupa) ou da aquisição de riquezas, ou dos cuidados com o corpo, ou de política ou de contratos particulares, entendendo em todos estes casos e chamando justa e bela à ação que mantenha e aperfeiçoe estes hábitos, e apelidando de sabedoria a ciência que preside a esta ação;" e será tido com injusta qualquer ação que dissolva esses elementos a cada passo, e será considerada ignorância a opinião que a ela preside. [13] Uma alma justa é uma alma saudável e harmoniosa. A justiça faz parte da natureza humana. 


\section{O JULGAMENTO DE SÓCRATES}

Naquela época, o direito natural era o único conhecido e era através dos ideais dele, que o filósofo acreditava que o justo natural não devia se sobrepor as normas. Com essas ideias avançadas para época - foi que Sócrates atingiu a ira dos governantes e aristocratas gregos; que desejavam a todo custo aplicar-Ihe uma sanção, a qual mais tarde veio a ser conhecida como pena de morte. Sócrates dialogava diariamente na Ágora Ateniense a respeito de vários assuntos, dentre eles, conhecimentos de vida, política, ciência e justiça. A elite local ficava intrigada com esses encontros, pois este filósofo espalhava ideologias de liberdade e palavras filosóficas para muitos ouvintes. Os gregos acreditavam que as pessoas não deveriam ter um 'estoque' limitado de ideias na cabeça, e que pessoas como Sócrates já haviam pensado demais. [14] A cidade de Atenas estava passando por uma fase difícil. Aproveitando-se desse contexto, Sócrates intensificou as reclamações e críticas ao governo e aos seus participantes, e aumentou mais ainda o discurso democrático. Todas as formas de governo e política eram sagradas para os gregos, pois havia a valorização demasiada da cidade (polis). Com sua argumentação engenhosa, Sócrates desmentia e questionava os ideais e as leis aplicadas pelos políticos. Desse modo, ele foi condenado por influenciar a juventude e trair os ideais democráticos de Atenas (polis). Afirmam que "Sócrates preferiu a coerência, em lugar da complacência, da anuência. Não the teria sido mais fácil renunciar às suas ideias, que encarnavam a rebeldia e a desobediência civil e com isso livrar-se da morte? Ele preferiu morrer, suicidando seu corpo, mas, permanecendo com suas ideias." [15] Há outras hipóteses que podem ser levadas em consideração para a análise da razão do julgamento. Dentre elas podemos destacar a noção de conhecimento para Sócrates, que muitas vezes ridicularizava alguém por seu saber e sarcasmo intelectual, ao mesmo tempo em que questionava e menosprezava as ideias políticas. Segundo relatos da época, o Oráculo de Delfos (portal através do qual os deuses se comunicavam com os mortais) teria mencionado que Sócrates possuía superioridade intelectual mediante os demais. Talvez, por isso, o pensador grego acreditava que seria capaz de "fazer a verdade vir à tona" na medida em que empreendia um debate com seus interlocutores. Mesmo tendo grande fama devido sua grande capacidade argumentativa, Sócrates não era um orador de todas as horas. A grande maioria dos debates políticos engendrados na Assembleia não contava com sua participação. Dessa forma, ao questionar ou empreender debate com um indivíduo, Sócrates acabava criando uma situação bastante contraditória. Ao mesmo tempo em que desdenhava das importantes questões políticas de sua cidade, era capaz de ridicularizar alguém por meio de seu sarcasmo intelectual. [16] Apesar de sua oratória magnífica, Sócrates não se defendeu de nenhuma acusação que the foi feita, preferindo questioná-las, sendo este, talvez, o pior de seus erros, o que poderia ter causado a tão grave pena atribuída a ele, qual seja, a de morte. Sócrates foi morto envenenado por acreditar que todo homem deve ser um ser pensante livre, devendo ter liberdade para expor suas ideias. Tal fato histórico chama mais atenção por acontecer em uma sociedade, caracterizada pela democracia e respaldo revolucionário, que valorizava, acima de tudo, o homem como ser pensante. 


\section{A REPERCUSSÃo do JULGAMENTO ANTIGAMENTE E A SUA INTERPRETAÇÃO NA MODERNIDADE}

A morte do filósofo terminou por conduzir os gregos a formação de pessoas indagadoras nome que mais tarde veio a ser sinônimo de ceticismo. Os céticos, assim, duvidavam de que as afirmações do conhecimento humano pudessem alguma vez oferecer a "verdade" sobre a totalidade do cosmo. Sócrates e Platão não haviam descoberto a verdade sobre o mundo; tinham apenas oferecidos diferentes concepções da verdade. Os céticos sugeriam que a maioria dos que se perguntavam sobre a verdade, e que, portanto não havia necessidade de novas indagações, ou por anunciarem que a verdade não podia ser encontrada, o que significava que não fazia sentido envolver-se na indagação intelectual. Ambas as posturas negavam a necessidade de dar continuidade ao processo. Ao contrario, os céticos afirmavam que a tarefa não tinha fim. A verdade era o objetivo, mas ficava muito além do entendimento humano (MORRISON, 2006: 62).

Sócrates não se dava por satisfeito com explicações convencionais; insistia em perguntar sobre o sentido das expressões, e desestabilizava a confiança que debatedor demonstrava ter em suas opiniões. Se, por um lado, esse processo argumentativo tinha por objetivo a busca da verdade ou da natureza essencial das coisas, por outro Sócrates não parece crer que o processo possa oferecer uma resposta absoluta. Portanto, Sócrates é de grande interesse para liberais modernos, que até afirmam que enquanto a verdade for objeto da pesquisa cientifica e filosófica, nunca se chegará à verdade absoluta. Ao contrario, Platão parece acreditar que os seres humanos são incapazes de compreender a sutileza desta posição e devem, categoricamente, acreditar que algumas coisas são simplesmente verdadeiras. Não verdadeiras no sentido do melhor que possamos argumentar em resultado de nossas metodologias e investigações, nem por concordância, mas simplesmente verdadeiras; verdadeiras em seu sentido absoluto. Assim, das heranças socráticas temos o ato de ser, que dá ato a todos os atos do homem. A sua vida, a sua existência, todos os atos que praticar dependem do seu direito de ser: ser homem e como homem manter relações com seus semelhantes. É o seu ser, assim, o fundamento de todo o Direito, pois o seu ser the é ontologicamente devido. E só se pode falar da virtude da justiça fundada no bem, reconhecendo-se a antecedência do ser do homem, como seu direito e no qual há de se fundamentar todo o Direito (GUIMARÃES, 1991: 298). Na época de hoje, da interpretação desse julgamento percebemos que o homem não pode viver isoladamente e sim conviver socialmente. Sócrates nos deixou o legado da influência, de procurar disciplinar este convívio, não apenas e primeiramente em seu benefício, mas em prol do bem comum, ainda que centrado em seu próprio bem, que entrevê lhe impor limitações, mas circunscritas no que diz respeito aos seus direitos fundamentais e que tenham por escopo a consecução melhor de suas finalidades.

\section{CONSIDERAÇÕES FINAIS}

O presente artigo se propôs a fazer uma análise dos conceitos de Sócrates. Seu direcionamento procurou discorrer sobre a importância do pensamento deste filósofo, construtor de 
discursos e ideias concisas e racionais. No percurso explicativo deparamos com a busca pela perfeição, entendida e explicada como a procura do saber. O conhecimento preconizado através do caminho ascendente e a questão do reconhecimento, onde temos que lembrar é recordar. $E$, em assim o fazendo, em razão do seu ser e do seu existir através da História, o Direito cristalizara-se ou evolve, fulgura ou se esvanece, é desrespeitado ou cumprido, vige ou é ab-rogados, torna-se eficaz ou inoperante; tudo segundo a contingência do homem no espaço. Sócrates foi o primeiro a questionar as ações humanas e os valores subjacentes a elas. Torna-se o inventor da ética. Trouxe um ensinamento profundo, até hoje ministrado e aprendido nas escolas do mundo, pois quando ao Ihe perguntarem por que aceitava o julgamento e sua morte, se eram tão injustos, respondeu: "é melhor suportar uma injustiça do que cometê-la". O que representa Sócrates? Não foi apenas um personagem histórico, que alguns duvidam da sua existência, que morreu em 399 a.C. mas sim o verdadeiro Sócrates vive dentro de todo ser humano. Ele representa a consciência, a capacidade de ser autêntico, de não se vender, de poder estar para além das opiniões dos demais, dos jornais, da televisão, das pessoas famosas, dos colegas, da família e poder ser autêntico consigo mesmo, de cada um pensar o que quer pensar, sentir o que quer sentir e fazer o que lhe diz a sua consciência sem esperar sempre a aprovação pública. As ideias da temperança, da coragem, da prudência e da justiça, se cristalizam no seu discípulo Platão, configurando-se como as quatro virtudes cardeais, remontando aos pensamentos primeiros de Sócrates para o tema da justiça, virtude inseparável do ser humano.

Desta maneira, não apresentando um caráter definitivo, o trabalho procurou discorrer sobre um dos mais importantes temas da filosofia e da história do Direito, qual seja a ideia de justiça e o julgamento do filósofo Sócrates, e sua aplicação e importância nos dias atuais.

\section{REFERÊNCIAS}

GRAU, Eros Roberto. O que é a filosofia do direito? São Paulo: Manole, 2004.

LAFFITTE, Jacqueline e BARAQUIN, Noëlla. Dicionário Universitário dos Filósofos. São Paulo: Martins Fontes, 2007.

CHAUÍ, Marilena. Introdução à história da filosofia: dos pré-socráticos a Aristóteles. São Paulo: Brasiliense, 1994

CHAUÍ, Marilena. Introdução à história da filosofia: dos pré-socráticos a Aristóteles. São Paulo: Brasiliense, 1994

MAGEE, Bryan. História da Filosofia. São Paulo: Edições Loyola, 2001.

ABRÃO, Bernadette Siqueira. A História da Filosofia. São Paulo: Nova Cultural, 2004. 
ARANHA, Maria Lúcia de Arruda e MARTINS, Maria Helena Pires. Filosofando - Introdução à Filosofia. São Paulo: Moderna, 2007.

BARRETO, Vicente de Paulo. Dicionário de Filosofia do Direito. São Leopoldo - RS e Rio de Janeiro RJ: Unisinos e Renovar, 2006.

Atlas básico de Filosofia - São Paulo: Escala, 2007.

A História llustrada da Grécia Antiga - São Paulo: Escala, 2007.

Revista Esfinge - SÓCRATES Mestre da Humanidade - Belo Horizonte: Nova Acrópole, 2007.

LALLANDE, André. Vocabulário Técnico e Crítico da Filosofia. São Paulo: Martins Fontes, 1999. SOUZA, Elton Luiz Leite de. Filosofia do Direito - Ética e Justiça. Porto Alegre: Núria Fabris, 2007.

GOTTLIEB, Anthony. O Sonho da Razão. Rio de Janeiro: Difel, 2007.

FERREIRA, Aurélio Buarque de Holanda. Dicionário da Língua Portuguesa. São Paulo: Nova Fronteira, 2004.

MAGEE, Bryan. História da Filosofia. São Paulo: Edições Loyola, 2001.

ABRÃO, Bernadette Siqueira. A História da Filosofia. São Paulo: Nova Cultural, 2004.

ARANHA, Maria Lúcia de Arruda e MARTINS, Maria Helena Pires. Filosofando - Introdução à Filosofia. São Paulo: Moderna, 2007.

BARRETO, Vicente de Paulo. Dicionário de Filosofia do Direito. São Leopoldo - RS e Rio de Janeiro RJ: Unisinos e Renovar, 2006.

Atlas básico de Filosofia - São Paulo: Escala, 2007.

A História llustrada da Grécia Antiga - São Paulo: Escala, 2007.

Revista Esfinge - SÓCRATES Mestre da Humanidade - Belo Horizonte: Nova Acrópole, 2007.

LALLANDE, André. Vocabulário Técnico e Crítico da Filosofia. São Paulo: Martins Fontes, 1999. SOUZA, Elton Luiz Leite de. Filosofia do Direito - Ética e Justiça. Porto Alegre: Núria Fabris, 2007.

GOTTLIEB, Anthony. O Sonho da Razão. Rio de Janeiro: Difel, 2007.

FERREIRA, Aurélio Buarque de Holanda. Dicionário da Língua Portuguesa. São Paulo: Nova Fronteira, 2004.

GUIMARÃES, Ylves José de Miranda. Direito Natural: visão metafísica e antropológica. 1. ed. Rio de Janeiro: Forense Universitária, 1991.

HABIB, Sérgio. Quando uma ideia leva à morte. Revista Prática Jurídica - Ano II - n. 19 - 31 de outubro de 2003.

MORRISON, Wayne. Filosofia do Direito: dos gregos ao pós-modernismo. São Paulo: Martins Fontes, 2006.

O julgamento de Sócrates e a Ágora Ateniense. Disponível em: < http://www.tecepe.com.br/olimpiadas/SocratesAgora.htm >. Acesso em: 01. Maio. 2010.

PLATÃO. A República. São Paulo: Martin Claret, 2002.

Revista do Direito [ISSN 1982-9957]. Santa Cruz do Sul, v. 2, n. 52, p. 60-70, maio/set. 2017. https://online.unisc.br/seer/index.php/direito/index 
SOUSA, Rainer. Julgamento de Sócrates. Disponível em: < http://www.alunosonline.com.br/historia/julgamento-de-socrates/ >. Acesso em: 28 abril 2010.

PLATÃO. A República. São Paulo: Martin Claret, 2002.

SOUSA, Rainer. Julgamento de Sócrates. Disponível em: < http://www.alunosonline.com.br/historia/julgamento-de-socrates/ >. Acesso em: 28 abril 2010

[3] "A temperança é uma espécie de ordenação, e ainda o domínio de certos prazeres e desejos, como quando dizem "ser senhor de si", e empregam outras expressões no gênero que são como que vestígios desta virtude.” PLATÃO. A República. São Paulo: Martin Claret, 2003, p. 125.

[4] "[...] a temperança, a coragem e a sabedoria, era o que dava a todas essas qualidades a força para que se constituírem, e, uma vez constituídas, as preservava enquanto se mantivesse nelas. Ora nós dissemos que a justiça havia de ser o que restava se descobríssemos as outras três." PLATÃO. Op.cit., p. 128.

[5] PLATÃO. Op. cit., p. 32 [6] Idem, p. 121 e 128.

[7] Idem, p. 129.

[8] Idem, p. 130.

[9] Idem, p. 131.

[10] "Não é, portanto, sem razão que consideraremos que são dois elementos, distintos um do outro, chamando àquele pelo qual ela raciocina, o elemento racional da alma, e aquele pelo qual ama, tem fome e sede e esvoaça em volta de outros desejos, o elemento irracional e da concupiscência, companheiro de certas satisfações e desejos." PLATÃO. Op. cit., p. 135. [11] Idem, p. 137 [12] Idem, p. 138 [13] Idem, p. 140.

[14] O Julgamento de Sócrates e a Ágora de Atenas. Disponível em: < http://www.tecepe.com.br/olimpiadas/SocratesAgora.htm> Acesso em: 28, Abril 2010. 2004, p. 02

[15] HABIB, Sérgio. Quando uma ideia leva à morte. Revista Prática Jurídica - Ano II - n. 19 - 31 de outubro de 2003, p. 20 e 21 [16] SOUSA, Rainer. Julgamento de Sócrates. Disponível em: < http://www.alunosonline.com.br/historia/julgamento-de-socrates/ >. Acesso em: 28 abril 2010, p. 02.

\section{COMO CITAR ESSE DOCUMENTO:}

DAVID, Ricardo Santos. O julgamento de Sócrates: Sócrates e o conceito de justiça: a repercussão do julgamento antigamente e sua interpretação atual. Revista do Direito, Santa Cruz do Sul, v. 2, n. 52, out. 2017. ISSN 1982-9957. Disponível em: <https://online.unisc.br/seer/index.php/direito/article/view/9443>. Acesso em: doi:http://dx.doi.org/10.17058/rdunisc.v2i52.9443. 